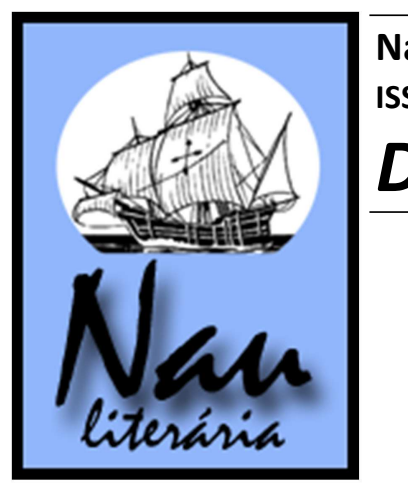

\title{
Formação, literatura e cultura: o rio de volta à terra
}

\author{
Christian Muleka Mwewa* \\ Ana Lúcia Sá**
}

\begin{abstract}
Resumo: O presente artigo tem como um dos objetivos verificar o ponto de inflexão da cultura como meio para a formação do sujeito. Por meio da análise do personagem Marianinho no romance $U m$ rio chamado Tempo, Uma casa chamada Terra, do moçambicano Mia Couto e da análise do personagem Noíto do romance Rioseco, do angolano Manuel Rui abordamos o encontro de culturas como nó de construção de conhecimento contextual. Nossas analises indicam que a educação de Marianinho demonstra os possíveis graus de relação que podemos estabelecer com o contexto social, e como a cultura de Noíto faz-se presente pelas evocações memorialísticas. Neste sentido, argumentamos que os caminhos percorridos pelos dois, Marianinho e Noíto, criam espaços de convergência de cultura, um espaço inter-, e de encontro de códigos entremeados em teias de progressivas compreensões.
\end{abstract}

Palavras-chave: Literatura, Formação subjetiva, Contexto, Mia Couto, Manuel Rui.

\begin{abstract}
This paper is intended to verify the point of inflection of the culture through education, through analysis of Marianinho character in the novel of Mozambican Mia Couto A River called Time, A house call Earth, and addressed the meeting of cultures as a node of construction of knowledge in the novel Rioseco, the Angolan Manuel Rui. Our analysis indicates that education Marianinho on the one hand, demonstrates the possible degrees of relationship that we can establish the social context from the cultural background that is allowed in the other, the culture of Noíto is present memoir by evocations point of comparison with the new reality that is and that it is made known by the hand of a child, Kwanza. In this sense, we argue that the paths traveled by two, and Marianinho, create space of convergence culture, an inter-space, and meeting fire codes in webs of progressive understandings.
\end{abstract}

Keywords: Literature, Subjective education, Context, Mia Couto, Manuel Rui.

\section{Introdução}

O presente artigo pretende verificar o ponto de inflexão da cultura por meio da formação, através da análise do personagem Marianinho no Romance intitulado Um Rio chamado Tempo, Uma casa chamada Terra, do moçambicano Mia Couto, e abordar o encontro de culturas como nó de construção de conhecimento no romance Rioseco, do angolano Manuel Rui. Os dois romances foram escolhidos, em relação às às demais dos dois

\footnotetext{
Doutor em Ciências da Educação com estágio doutoral na Université Paris I Panthéon-Sorbonne (2008). Professor no PPG em Educação da UNISUL. Membro da Equipe Editorial da Revista POIÉSIS.

${ }^{* *}$ Doutora pela Universidade da Beira Interior (Covilhã - Portugal). Autora de artigos e de livros sobre reflexões sociológicas a partir da literatura, com vista à formação de cidadania em Angola. No momento desenvolve o seu pós-doutoramento na área de Literatura Africana com o financiamento da Fundação para Ciência e TecnologiaFCT (Portugal).
} 
autores, por expressarem de forma pontual as convergências, divergências e tensões entre culturas materializadas nos binómios: familiar/escolar; local/global; dentro/fora dentre outros.

Neste sentido, alertamos para a observação do movimento dos conceitos que balizam as nossas análises, Formação e de Cultura, pois o mesmo expressa a dificuldade apreensão e a não necessidade de enclausurá-los dentro das camisas-de-forças conceituais. Portanto, os tomamos de forma constelar, ou seja, a sua compreensão deve resultar da relação dos elementos que figuram no contexto onde são empregados.

Marianinho conjuga a formação dita escolar com a familiar (local e não-escolar) diante do inevitável: a Morte e o Desejo. Este personagem percorre uma linha limítrofe na qual as subjetividades pretendidas pelos mecanismos de formação escolar são subvertidas diante da necessidade de se relacionar com o mundo objetivo local. Assim, Marianinho desencadeia um sábio estrelaçamento dos dispositivos sociais escolares e familiares a partir da sua rela-ação com o real e com o imaginado, contra o qual não se pode argumentar.

No romance Rioseco, Manuel Rui entrelaça terra, rio e mar, oferecendo a possibilidade de várias construções culturais a concurso nas relações entre os personagens. Noíto e Zacaria, um casal de migrantes, e a comunidade de pescadores de uma ilha registram os diversos códigos na escrita de um romance que dá a conhecer novos modos de formação para além da educação escolar que, aliás, surge desconfigurada.

Os dois romances, portanto, cada um na sua particularidade, oferecem contributos sociológicos para pensar as confluências culturais no processo de formação subjetiva em contextos cada vez mais cambiantes.

\section{Implicações objetivas na formação do sujeito: Marianinho}

Para verificar, como ponto de inflexão da cultura, as implicações sociais da formação, tomamos como exemplo a análise do personagem Marianinho no Romance intitulado Um Rio chamado Tempo, Uma casa chamada Terra, de Mia Couto. Marianinho conjuga a formação dita erudita (escolar) com a cultura popular (local ou não escolar) diante do inevitável: a Morte e o Desejo. O primeiro elemento torna-se o motivo do seu regresso, diante do qual ele explicita toda a incongruência na sua formação e o paradoxo que esta estabelecera no sujeito. A morte se torna um guia para a percepção dos mecanismos formativos em Marianinho no processo de alcançar o seu objetivo, que é o enterro do avô/pai, o dito Mariano, respeitando os rituais impostos pela comunidade.

Já o Desejo (sexual), pela primeira vez, concretiza-se diante de uma situação na qual Marianinho é completamente tomado por uma força alheia em sua condição e num espaço 
onde a escuridão o igualava à amante. Ou seja, a fortaleza da sua formação não o ajuda nesse momento, pois está entregue ao desconhecido, diante do qual encontra-se indefeso, restandolhe somente a entrega. Há um instante de tomada de consciência, quando hesita, em respeito ao morto que se encontrava na sala, para não ferir a tradição. Marianinho, contudo, é vencido pelo querer da carne e se insinua de forma a instalar uma outra problemática familiar: deflagrar uma relação sexual entre sobrinho, instruído, que vive afastado e que viajou no espaço, e a tia, que viajou no tempo.

A segunda vez que o Desejo se concretiza é em sonho, ou seja, em outro espaço obscuro, onde Marianinho novamente é destituído da sua subjetividade e cede ao controle daquela que o possui, desta vez, porém, para pôr fim à problemática central do seu regresso e fechar o seu dever para com o enterro do seu avô.

A sua ação, nesse universo, assenta-se sob uma linha limítrofe na qual as subjetividades pretendidas pelos mecanismos presentes na formação escolar são postas em evidência diante da necessidade de relacionamento com o mundo objetivo tradicional (local). Assim, Marianinho desencadeia um sábio entrelaçamento dos dispositivos sociais escolares e locais (citadinos e ilhéus) a partir da sua relação com o real, ou seja, com o cumprimento do enterro do seu avô/pai, o qual se torna propedêutico para trazer à tona diversas problemáticas que afligiam o local no seu processo de pós-colonialismo. Essa relação com o social se dá em dois níveis: o real, que acabamos de explicitar, e o imaginado, que se dá nas cartas do falecido e contra o qual fracassa qualquer nível de argumentação. Dessa forma, diante das cartas, o protagonista somente tinha de obedecê-las e, por mais que algumas vezes relutasse, acabava obedecendo. A ilustração, no sentido de formação, via-se atada, sem instrumentos de mediação suficientemente preparados diante do obscuro.

Marianinho deflagra os dilemas pelos quais o sujeito intercultural passa ao se deparar com situações que exigem posicionamentos que respeitem outros sujeitos pertencentes a um universo cultural do qual ele se diferencia. O personagem privilegia uma convivência não violenta com os pertencentes ao universo ao qual ele regressa. É a inércia voluntária, percebida quando os policiais arbitrariamente o prendem e o amarram na prisão. "Espantado, nem reajo. Dócil de tanta insensatez sou conduzido à esquadra". (COUTO, 2003, p. 202-203). A violência, portanto, emudece qualquer possibilidade de crítica, restando-lhe apenas agir por inércia à espera da restauração da sensatez humana, principalmente nos seus agressores. Essa atitude representa a falta de condições sociais para o combate à violência infringida aos que não pertencem à esfera do poder. Somente neste nível é que se pode dizer que Marianinho se iguala aos locais. Porém, a influência familiar logo o liberta do poder dos agressores, e essa 
libertação mais uma vez o libera para cumprir o seu intento. Esse conflito torna-se também uma denúncia do seu distanciamento espaço-temporal em relação ao poder local, que por essa atitude mostra como ele continuava um ser comum para as instâncias de poder. Assim, elabora uma subjetividade intercambiante, manejando a racionalidade escolar "Dócil de tanta insensatez" (aquela da escola) e a inércia dos subalternos locais “...nem reajo ...” (aquela que diz respeito à ancestralidade na tradição familiar e local).

Marianinho critica os limites do meio onde convive a partir de uma posição de fronteira, ou seja, do lugar daquele que retorna à terra natal respeitando os valores locais a partir dos quais se formou. Assim, ele pôde se colocar na posição daquele que vem (e vê) de fora. É com o olhar de afastamento, porém de dentro (na relação), que este se relaciona com a realidade que lhe é apresentada da sua cidade natal. A morte do seu avô torna-se indissolúvel diante dos mecanismos que estruturam a cerimônia do funeral a ser realizada. $\mathrm{O}$ amor carnal suscitado pelo "vulto" (o desconhecido e não identificável) que o possui no escuro, sem identificações declaradas, mas palpáveis, dá lugar ao indeterminado e ao inconsequente da sua ação. Esta, porém, era requerida pela e na sua imaginação, pois ele declaradamente se mostra ciente da possível impunidade diante do papel social que exerce. Ele era quase um forasteiro, que podia infringir as regras locais. Assim, por instantes, pôde imaginar que era com a tia que estava fazendo amor, porém certifica-se de que não era, e o ato segue. No início, luta contra aquilo que está para suceder (como em algumas culturas africanas em que eram proibidas as relações sexuais no período de luto); depois, o proibido se torna desejável. Estes são pontos providenciais que o livram da obediência às regras morais que regem o lugar, como, por exemplo, a proibição de uma relação sexual entre tia e sobrinho. É somente nesse lugar que se encontra o refúgio para poder escapar de tais regras. A sua formação escolar lhe garante, portanto, possibilidades de reelaboração das diretrizes culturais enquanto mecanismos que estruturam as relações entre os sujeitos numa dada sociedade. Este fato também é exemplificado quando o avô o escolhe para dirigir a cerimônia do funeral.

A possibilidade de racionalizar, ou seja, de elaborar de forma sistemática a compreensão dos mecanismos sociais, permite a Marianinho transcendê-los, observando a sua trajetória, sem o ônus social com qual outro cidadão da Ilha teria que arcar. É, pois, na diferenciação que ele pode agir na restauração da ordem familiar e, por extensão, da ordem social. O segundo ato sexual com Nyembeti, dessa vez em sonho, também se torna funcional pela não equidade de posição entre os envolvidos (Marianinho e Nyembeti), ou seja, dessa vez, por estarem na dimensão do sonho, os papeis são invertidos. Dessa forma, quem ordena e conduz o ato é Nyembeti, que socialmente representava uma categoria rejeitada, ou seja, aquilo que não se 
podia ser (pobre e sem domínio da língua corrente) e que, portanto, deveria ser rejeitado. A consciência de querer se manter diferente, contudo, liberta-a da obediência social, pois isso a protegia, configurando-se como refúgio pessoal. Os desajustados sociais possuem, assim, uma permissividade maior na mais pura expressão de liberdade perante a sua inadaptabilidade. Tornam-se, entretanto, o objeto ao qual se destina o ódio daqueles que diuturnamente buscam adaptar-se no mesmo processo dos produtos de consumo para quem são minuciosamente produzidos.

Nyembeti não falava a língua "oficial", e Marianinho tinha que, de certa forma, "decifrá-la" como a um estratagema, o que tornava possível a funcionalização da sua formação (escolar e familiar) no contexto, enquanto a fragilizava. Do alto de seu saber, portanto, ele poderia possuí-la, assim como, a partir de outros mecanismos de poder verticalizado, ela se entregara ao tio de Marianinho. Para Marianinho, existia a permissividade do "tutor" da moça, num ato de reconhecimento da possibilidade de projetar-se para um outro nível social ou de protegê-la da exposição carnal protagonizada pelo seu tio.

Por reconhecer a condição social de Marianinho, seu avô/pai lhe confiou o proceder do seu enterro juntamente com o desabrochar dos segredos que o cercavam. Isto é, o contexto que cercava o ato que causou a sua morte. Revelava-lhe periodicamente os elementos de desterritorialização das pessoas na terra (sociedade), no sentido de torná-los piores no ponto de vista dos habitantes. Esse processo forçava-os a, literalmente, mudar de lugar, por isso a expressão desterritorialização se faz importante, pois ela não se remete somente ao subjetivo, mas também ao objetivo. A partir da sua formação, adquirida na outra "margem do rio", procede como que uma odisseia de reelaboração, no sentido de uma longa viagem por dentro do funcionamento do grupo familiar. Esse processo possibilita a percepção de alguns nós na formação de Marianinho, pois, num fazer quase artesanal, ele percorre os caminhos obscuros que orientaram aquele estado social. As cartas do seu avô se configuram numa exteriorização do seu raciocínio, pois são elas que o guiam em seu percurso. A "restauração" das relações familiares se dá por meio do esclarecimento, no sentido de clarear, dos "desígnios" dos sujeitos envolvidos. Sem a figura de Marianinho, contudo, isso não seria possível. Mas ele se reveste do papel de observador, daquele que aponta as máculas que obscureceram tais relacionamentos, e ocupa o lugar de castrado, como um eunuco das bases culturais "da nossa terra”, como diria o patriarca, mas desfruta da representação social que exerce justamente por possuir algo aquém das bases culturais. Exerce, assim, a função de restaurador da ordem, ao apontar onde está a disjunção, mas a partir de fora, onde não reproduz as bases culturais e pode, assim, dar "nomes" ao objeto sem violentá-lo. 
Esta, portanto, é a função daquilo que é concebido a partir de elementos internos de um contexto, porém, com a função de manter em evidência a verdade desse contexto sem a ela sucumbir.

Assim, Marianinho reverbera as implicações dos elementos da formação, engendrados na sociedade como um todo, para gerenciá-los frente à problemática em que a morte do seu avô o colocou. Ao retornar ao seu contexto original, sem essencialismos, a forma como Marianinho se relaciona com a formação que adquiriu fora não evidencia um comportamento a ser admirado por aqueles que apenas puderam viajar no tempo. Por mais que questionasse a formação local, ele não a desrespeitou, e tentou por dentro dela mostrar as suas incongruências, pois “....a exatidão do fenômeno, num sentido que se desenvolve somente no exame do próprio fenômeno, converte-se em garantia de sua verdade e em estímulo à sua falta de verdade" (ADORNO, 1974, p. 31).

As implicações entre a formação ensinada (própria das instituições de ensino) e a vivenciada (presente no cotidiano familiar), em Marianinho, deflagram um conflito intrasubjetivo semelhante àquele da obra de arte com o social que a concebe e sem o qual ela não seria possível. A segunda formação o constitui na condição de sujeito, mas, sem a primeira, a segunda não seria possível. É importante ter claro que "las práticas no son meras ejecuciones del habitus producido por la educación familiar y escolar (...) $)^{1,}$ (CANCLINI, 2006, p. 158).

Portanto, a partir da relação entre a formação familiar e escolar em Marianinho, instaura-se um comportamento reflexivo (no sentido de ser agente e paciente desta relação) no próprio sujeito, que se relaciona com tais conteúdos formativos a partir de “...uma atitude de conhecer objectivamente [...] como a atitude adequada" (ver ADORNO, 2000, p. 271).

A morte do avô fez com que o pai "social" (pois o biológico era o avô/pai) quisesse se alienar do mundo objetivo, e com que o tio - Ultímio - quisesse a todo custo que os moradores, mais precisamente os seus familiares, aceitassem os desígnios da nova configuração social da Ilha. Essas atitudes podem ser equiparadas mais proximamente com a função da obra de arte na sociedade. Ou seja, esta quer se manter alienada do mundo objetivo sem deixar de funcionalizar (implementar) novas configurações no social a partir da sua intervenção. Num contexto mais geral, Marianinho não mais pertence à Ilha, porém a sua intervenção é primordial para a continuidade desta enquanto conjunto social. Mas, num contexto mais específico, essa dupla ação, em Marianinho, dá-se no pensamento de forma

\footnotetext{
${ }^{1}$ As práticas não são meras execuções do habitus produzido pela educação familiar e escolar. (Tradução livre dos autores).
} 
latente através, por exemplo, do desejo intenso de possuir a sua própria tia. Assim, "le besion authentiquement critique de la pensée, de s'arracher à la fantasmagorie de la culture est capté, canalisé, conduit à la conscience fausse" (ADORNO, 2007, p. 109). É essa falsa consciência (em resumo: acreditar que aquilo com que nos relacionamos seja a verdade faz com que não almejemos ir além dela), causada pelo desejo contextualmente proibido, que é clarificada através do respeito que Marianinho possui pela formação familiar, ou seja, respeito aos ensinamentos que recebera no contexto familiar. Porém, sucumbiu ao desejo e manteve, passivamente, relações sexuais em dias de luto. A partir de um misto de racionalidade (a busca da compreensão do estado das relações familiares) e mito (a crença nas regras do sepultamento do seu avô), Marianinho age como um indivíduo privilegiado, possuidor de um mecanismo duplicado que o permite uma desenvoltura de acordo com a contingência, fazendo uso da formação, digamos assim, que a situação demanda, pois "O que é que fica tão longe que toda a gente vê melhor é dentro de nós? O horizonte. Pois eu estava além do horizonte" (COUTO, 2003, p. 202). Esta performatividade o possibilita não sucumbir de imediato à nova regulação social, preconizada por Ultímio, que projetaria a Ilha numa esfera mais ampla do ponto de vista administrativo. Ou seja, a Ilha passaria a desfrutar dos mesmos mecanismos sociais que funcionalizam diferentes partes do mundo na esfera do consumo e das relações laterais. Portanto, se "des valeurs éternelles [sont] compromises, il ne reste plus rien que la confiance en la sainteté de l'essence [de l'] Être privilégiée par rapport à tout ce qui est chosifié $^{3 ”}$ (ADORNO, 2007, p. 115). Assim, este Être privilégiée (ser privilegiado) deve escapar do processo prioritariamente reificante empreendido pelas forças reguladoras a partir de promessas de boneur (no sentido de felicidade).

Coloca-se também no sujeito uma falsa necessidade de reconciliação entre elementos aparentemente opostos: a formação familiar e a escolar. Falsa, porque estas se conjugam no sujeito de forma ambivalente; e aparentemente, porque estas não podem ser lidas somente em concorrência, mas, também, em correlação, uma vez que são partes do mesmo sujeito. A tensão entre ambos pode ser pensada como a mola propulsora, e uma reconciliação seria o suficiente para enferrujá-la. Assim, a incidência que as duas formações têm no sujeito resulta numa ação única, ou seja, diante das recomendações do seu avô, por exemplo, Marianinho manifestava uma ação, e não sabemos qual formação funcionalizou tal ação. Essa complexa

\footnotetext{
${ }^{2}$ As razões autenticamente críticas do pensamento, de se afastar da fantasmagoria da cultura são cooptadas, canalizadas, em direção à falsa consciência. (Tradução livre dos autores).

3 Os valores são compromissos, não resta mais nada do que a confiança na sanidade da essência do ser privilegiado frente a tudo que é coisificado. (Tradução livre dos autores).
} 
matemática contraria, mais uma vez, as posições que insistem em dividir o mundo em dualismos petrificados. Marianinho encara essa dualidade contextual de forma equalizadora.

A possibilidade necessária de racionalizar coloca Marianinho em uma situação que respeita a forma como o contexto funciona sem o desprendimento dos objetivos traçados anteriormente. Temos, assim, um exemplo mais pontual da dinâmica de Marianinho entre as formações às quais ele era assujeitado e na funcionalização destas, diante das quais ele se constituía sujeito sem atender de imediato às necessidades sociais que se colocavam diante de si.

\section{Para além da educação escolar: Noíto e Kwanza}

O rio, quando deságua no mar, empreende o retorno à terra no romance Rioseco, do angolano Manuel Rui. Estas metáforas concorrem para um duplo sentido: conjugam os caminhos da migração motivada pela guerra civil (com a consequente fuga para condições deficientes de sobrevivência) e procedem a uma síntese da aprendizagem da vida em comunidade.

Zacaria e Noíto são um casal que palmilha o país até chegar à região litorânea, onde se situa a capital. Sem a proteção sufuciente necessária, navegam da cidade até uma ilha, sua última paragem. Só então findam os anos de errância, e acontece a única experiência que faltava. Então, a inauguração do presente traz a paz e a reintegração numa vida comunitária (RUI, 1997, p. 9, 14, 23, 131).

É Mateus quem os leva até esse espaço, periférico em relação às lógicas do Estado angolano. Ao longo da narrativa percebe-se que, manifestamente, esse espaço não abrange todos os que nele se integram.

As personagens que mais destaque ganham na obra são Zacaria, Mateus e Noíto. Para Ana Mafalda Leite, o primeiro personifica o rio, o segundo, o mar, e Noíto, "metade rio metade mar" (1998: p. 75). Zacaria é rio: "Já te falei que eu sou o rio" de águas que nunca param (RUI, 1997, p. 206). E é carpinteiro, manobrador de um elemento natural, numa atividade que coloca ao dispor da nova comunidade. Mateus é mar e representa o povo que habita a Ilha do Mussulo, a suposta ilha real, espelho da ilha literária de Rioseco. Os axiluanda são igualmente residentes na Ilha de Luanda e amplamente estudados por Ruy Duarte de Carvalho na obra Ana a Manda, Os Filhos da Rede. A sua principal atividade econômica é a pesca, e diferem-se da restante população da cidade por caracteres distintivos, que acabam por estigmatizar esse grupo (CARVALHO, 1989, p. 31, 314). Quanto a Noíto, seria ele rio e mar simultaneamente? 
Rio que deságua num mar pelo caminho empreendido, sim. Mar, creio, na condensação que faz com a terra. De mar e terra, então, notamos que os discursos de pertença e de localidade de Noíto variam, de acordo com o que sente da parte das pessoas da Ilha, dispondo a sua própria sorte naquele local e junto delas. Como essa dicotomia, há outras que sustentam a obra: o azar e a sorte, a vida e a morte, a guerra e a paz, o homem e a mulher, o lembrar e o esquecer. A essencialidade do romance está nas dicotomias das quais se faz uma vida, um percurso de um personagem e o de um território, e nas permanentes conflituosidades entre o que modernamente seria mais aceitável e o que tradicionalmente surge como a única via oferecida para o sucesso.

Em Rioseco, a primazia é dada ao universo feminino. É a mulher que condensa tempo e espaço. É dela, de Noíto, que conhecemos o universo mais íntimo, as suas sensações e os seus pensamentos, em longos monólogos interiores, discursos sem ouvinte que, ao contrário do explicado por Sallenave (s.d., p. 111), não são anteriores a uma organização lógica do pensamento, mas a sua plena elaboração. Noíto aproveita os momentos solitários para organizar o seu mundo e para compreender o seu passado e o seu presente.

Para a compreensão do presente e para a etapa formativa que passa da compreensão à actuação, Noíto escolhe aculturar-se dos modelos encontrados na Ilha. O universo da oralidade surge no contexto de produção e de recepção de mensagens de tradução e de aprendizagem de mundos por Noíto e por Kwanza, personagem menino que partilha o seu nome com o do maior rio de Angola. É Kwanza quem revela a Noíto os "segredos daquela ilha" (RUI, 1997, p. 57). É Kwanza quem quebra com Noíto as regras que estipulam a marcação de gêneros nas tarefas quotidianas. O manejo do barco e das artes piscatórias cabem aos homens e, com os ensinamentos de Kwanza, a Noíto (RUI, 1997, p. 133, 186-187). A educação radica numa cronotopia transgressora e dá a Noíto o conteúdo de fronteira discutido anteriormente com relação a Marianinho, personagem de Mia Couto.

É significativo que o papel de tradutor cultural caiba a uma criança. Como o é também o fato de ser Kwanza quem ensina a tradição, e não um mais-velho, que, a princípio, seria reconhecidamente mais sábio:

Na minha terra falam que uma pessoa quando quer saber das outras terras, deve primeiro, andar com os miúdos. Se tu quiseres saber como se pode amadurecer, nunca perguntes numa fruta já madura. Pergunta, primeiro, numa noxa nova. Uma noxa que está ver outras se amadurecerem, outras caírem da árvore ainda verdes e ela com vontade de amadurecer (RUI, 1997, p. 187).

A infância é um tempo primordial de construção do futuro e, na aliança com a voz de uma mulher, oferece partilhas de códigos para a aprendizagem do mundo à parte do contexto 
de guerra civil que se vivia em Angola. Manuel Rui transporta para o seu romance não apenas um espelho da realidade social, mas vai muito além dele, ao produzir a sociedade à margem do conflito, centrada nas relações comunitárias. Entre essas relações, destaca-se, nesta comunicação, centrada na educação, a que une Noíto e Kwanza.

No que toca ao menino, o que ele aprende com Noíto contrasta com as condições de escolaridade precárias e com as outras estórias inventadas com os seus companheiros de idade. É Noíto quem lhe conta "quase de missosso" - histórias tradicionais de ficção (ver FONSECA, 1996, p. 45) - histórias de personagens concretas que passam da realidade para “os seus encantos infantis de ouvir" (RUI, 1997, p. 404). É Noíto quem ensina a Kwanza, menino com nome de rio, o que é a realidade fluvial nas atualizações constantes que faz do universo da terra em que sempre viveu.

A educação em Rioseco vai muito além do sistema escolar, que surge num contexto desregulado e de carência, de falta de uma educação formal em condições dignas (RUI, 1997, p. 57, 203-204, 251). Como meio de substituição, Noíto e Kwanza encenam as possibilidades oferecidas por uma educação pela partilha e pelo poder da palavra. Como sintetiza Ana Mafalda Leite, Noíto e Kwanza representam "a conjugação entrosada do velho com o novo, numa aliança de sabedoria reaprendida. Enquanto ela inicia o menino no mundo do interior, ele ensina-lhe o mundo da ilha" (1998, p. 75).

$\mathrm{Na}$ base do sucesso social de Noíto encontramos as suas qualidades extraordinárias (reais ou presumidas?), que não raro ultrapassam o domínio meramente humano. A noção weberiana de carisma tem nessa personagem um exemplo acabado, enformado na sua relação com os habitantes do espaço que foi tornando seu. De estranha a amiga preferencial de Kwanza, Noíto vai se transformando em alguém respeitado por toda a comunidade por nela reconhecer os poderes de operar sobre o tempo e por transgredir regras.

São as necessidades de entrelaçamentos culturais comunitários as relevadas no romance, e a partir delas é que se dão as escolhas das personagens em aprender e em empreender mecanismos de sobrevivência cultural e social.

\section{Considerações Finais}
...os rios que percorrem o imaginário do meu país cruzam territórios universais e desembocam na alma do mundo. (COUTO, 2009a, p. 11)

O mar é só assim por causa dos rios que lhe trazem a água. Os rios é que enchem o mar. (...) 
Sem a nossa terra, sem os rios que atravessam muito tempo, devagar e depressa, depressa e devagar, a secar e a encher na chuva, onde é que estava o mar? (...) Não há mar sem rio.

(RUI, 1997, p. 90)

A partir do exposto é possível argumentar que a forma como esses personagens, quando tomados na condição de seres sociais, manejam a formação que receberam frente às implicações apresentadas pela realidade sugere possíveis caminhos para uma outra forma de diálogo com os dispositivos sociais num contexto específico. Esses caminhos, se pensados como métodos elaborados pelos personagens, podem sugerir a descodificação dos elementos que atravessem a nossa realidade para melhor compreendê-la.

É na constituição de um sujeito atento às ideologias que podemos localizar uma das possibilidades de se configurar o novo na ordem social, uma vez que a ordem constituída não o dominou totalmente. Atentos para o fato de que Theodor Adorno, por exemplo, em sua obra, não coloca a brecha do sistema de forma evidente, e muito menos receituária, compreendemos que essa possibilidade pode ser materializada nas ações de Marianinho e na problematização das dicotomias questionadas no romance Rioseco. No seu contexto, Marianinho funcionaliza a formação da qual é constituído, apontando para o logro do sistema que, uma vez deflagrado, permite a busca pela implementação de uma outra maneira de se relacionar com este. Noíto e Kwanza, por exemplo, fazem da infância (a fruta imadura) um local privilegiado do saber. Só a esperança de que essa relação pode ser diferente da atual já nos renova na esperança de um mundo diferente. Portanto, esse desejo radica na ideia de que “...vraie serait la pensée qui souhaite quelque chose de juste" (ADORNO, 2007, p. 118). A todo o momento Marianinho busca esse novo para si e para os que vivem na Ilha, por meio de ações que restabeleçam o convívio entre os habitantes diante dos novos condicionantes, como, por exemplo, a independência política e administrativa da Ilha. Essa ação não deve necessariamente instaurar uma forma justa de governo, pois este se dá de acordo com cada povo. Porém, a independência do domínio externo pode deflagrar uma dependência infligida pelos iguais que se diferenciam na busca da serventia do outro, conservando assim a forma de le canon de la culture officielle que, no caso de África, é regido por uma cor de pele diferente, porém carrasca com os seus iguais. É contra o desespero dessa conformação que todas as indicações da dynamique historique que apontam para uma formação social diferente devem se direcionar. A ilusão da mudança ou a cor da pele não podem ofuscar a compreensão do

\footnotetext{
${ }^{4}$ Verdadeiro será o pensamento que deseja algo de justo (Tradução dos autores).
} 
funcionamento dos mecanismos que nos assujeitam, para que possamos “exiger de l'autre un comportement humain" (FANON, 1971, p. 186) que esteja além da educação que teima conformar-nos.

Se, por um lado, a educação de Marianinho, de forma manifesta, demonstra os possíveis graus de relação que podemos estabelecer com o contexto social a partir da formação cultural que nos é permitida, por outro, a cultura de Noíto faz-se presente pelas evocações memorialísticas, ponto de comparação com a nova realidade que encontra e que lhe é dada a conhecer pela mão de uma criança, Kwanza. Os caminhos percorridos pelos dois criam espaços de convergência de cultura e de encontro de códigos acionados em teias de progressivas compreensões. Trata-se de um apelo a um desenvolvimento sustentado, no contexto, e da colocação de questões ao país. São desafios para ultrapassar obstáculos e para aceitar as dinâmicas operativas num contexto localizado, nele surgindo como as mais adaptadas. Afinal, não pensaremos nós com a nossa cultura?

\section{Referências}

ADORNO, Theodor Wiesegrund. Teoria estética. Lisboa: Edições 70, 2000.

. Filosofia da nova música. São Paulo: Perspectiva, 1974.

. Dialectique négative. Paris: Payot, 2007.

CANCLINI, Nestor Garcia. Diferentes, desiguales y desconectados: mapas de la interculturalidad. Barcelona: Ed. Gedisa, 2006.

COUTO, Mia. Um rio chamado tempo, uma casa chamada terra. São Paulo: Companhia das Letras, 2003.

.. E se Obama fosse africano? E outras interinvenções. $2^{\mathrm{a}}$ edição. Lisboa: Editora Caminho, 2009a.

FANON, Frantz. Peau noire, masques blancs. Paris: Éditions du Seuil, 1971.

FONSECA, António. Contribuição ao Estudo da Literatura Oral Angolana. Luanda: Instituto Nacional do Livro e do Disco, 1996.

LEITE, Ana Mafalda. Oralidades \& Escritas nas Literaturas Africanas, Lisboa: Edições Colibri, 1998.

RUI, Manuel. Rioseco. Lisboa: Cotovia, 1997.

SALLENAVE, Danièle, "Sobre o «monólogo interior»: leitura de uma teoria", in AA. VV., Categorias da Narrativa, Lisboa: Veja, s.d., pp. 103-124. 